\title{
Research On Risk Management Of Power Engineering Project Based On Fuzzy Comprehensive Evaluation Method
}

\author{
LI Jia-ming \\ Heilongjiang daqing oilfield limited liability company production operation department \\ lijiaming@cnpc.com.cn
}

Keywords: Power engineering; Project risk; Index system; Multi-level fuzzy comprehensive evaluation

\begin{abstract}
With the increase of investment in electric power engineering project and the rapid development of electric power construction market, the risk factors and risks of the project are greatly increased. The traditional power project management methods can not meet the needs of modern enterprise development, the scientific and standard method of risk management for power engineering project is imperative. In this paper, based on the analysis of the conception and characteristics of electric power project risk management, the main influencing factors of power engineering project risk are identified, the risk evaluation model of power engineering project based on fuzzy comprehensive evaluation method is established. This paper provides theoretical basis for evaluation of the risk level of power engineering projects scientifically and effectively and strengthening the risk management of power industry.
\end{abstract}

\section{THE RESEARCH BACKGROUND}

Since the reform and opening up, China's rapid development of national economy, and in a straight line rise, in recent years people the power of the city Need to gradually increase, power load excessive overloading of the project, the power shortage phenomenon frequently lead to everywhere is electricity phenomenon is gradually increased, to our country national economy sustainable development and people's normal life caused great obstacles. Power engineering project risk management and closely related to the electric power enterprise development in the future, because many companies don't pay much attention to power engineering project risk management and risk assessment, and huge losses encountered in the operation and management, there are even making companies the possibility of bankruptcy. ${ }^{[1]}$

Therefore, only through the in-depth research and power engineering project risk management, using the dynamic and comprehensive Methods to comprehensive engineering project risk management, to form a power engineering project risk identification system as soon as possible, to cause the influence factors of power engineering project risk largely selected, using the appropriate measures to control and prevent the happening of the risk, so can guarantee the stability of the electric power project to be power engineering project to realize win-win situation of economic and social benefits \section{MANAGEMENT \\ II POWER ENGINEERING PROJECT RISK}

A. The meaning of power engineering project risk management

Simply put, electricity power engineering construction project risk management is to project the possible and potential risks, risk management through the use of technology to manage these risks. Electric power engineering construction project risk management organization and management personnel in the process of electric power engineering projects may lead to project the uncertainty of the loss of project risk identification, risk prediction, project risk analysis, risk assessment and project risk management, at the lowest cost to ensure maximum security of the project. ${ }^{[2]}$

Power engineering project risk management have the prescribed standards for management and achieved expected, power engineering project risk management in the power engineering construction project general standard, under the power of engineering project risk identification, and adopt quantitative description and discussion, and application of the corresponding risk management plan, to prevent power engineering project risks. Power the overall goal of the project specific have the following items: create good security for power engineering project implementation construction environment; Power engineering project cost saving, in order to make power engineering project investment do not break through the limit; Ensure power engineering project according to the established with rhythm, the plan to carry out; Ensure the quality of electric power engineering projects; Keep controlled power engineering project has been in good condition; As far as possible to reduce the external environment and internal factors on the electric power engineering projects of resistance; Finally let power engineering project smooth implementation.

B. he characteristics of the electric power engineering project risk management

Power engineering project operation cycle is long, is the nature of relatively cumbersome integrated project, the project risks exist in every link in the process of electric power 
engineering project implementation, closely related to electric power project construction activities. These risk factors are interdependence between the organic whole, the characteristics of electric power engineering project risk is as follows:

(1) risk of diversity. In specific power engineering project construction, with an a variety of risks, not just one or two function in the power engineering project risk, for example, economic risk, natural risk, contract risk, legal risk, political risk and collaborators risks, etc. The risk each other relatively complicated relationships exist in . $^{[3]}$

(2) risk regularity. While there exist a lot of in the power engineering project, uncertainty, risk factors, but the occurrence of these risk factors is not chaotic, no rules to follow. Because power engineering project are the change of the external environment of construction and development projects will generate internal coordination, therefore, damage problems also exist in project coordination, can through some means, the technical measures and experience to make predictions.

(3) the influence of risk overall. Existed in the electric power engineering project risk is generally do not belong to the unilateral risk, do not belong to the specific deadline or specific Angle, usually from the overall point of view. Project risk occurs are continuity and potential relevance, for example the bad geological environment factors can lead to suspension of electric power project, resulting in the overall project construction is not perfect in the future. Even lead to power engineering project construction period delay, expansion of the construction costs, these factors are all the electricity the smooth implementation of the project is a lot of damage. Even part of the small problems can also along with the development of power engineering project construction process, slowly spread the harm.

\section{IDENTIFICATION}

\section{IIIPOWER ENGINEERINgG PROJECT RISK}

A.The meaning of power engineering project risk identification

Project risk identification is to find those who can strongly affect the project successfully completed the goals of the main risk factors, and the basic features of the major risk factors, specific bad impact on what parts of the project will be identified. Power engineering project risk identification, the purpose is to find out what factors influencing electric power engineering project risk. Power engineering project risk identification is the basic premise of power engineering project risk management conditions, only for the kinds of risk factors and risk events, causing reason, damage degree, good analysis, identification and judgment, and to develop appropriate control measures for effective risk prevention. ${ }^{[4]}$

B.The content of the electric power engineering project risk identification

With other engineering project risk identification is the basic process and content of the same, power engineering project risk identification, the difference of their difference only lies in the object recognition. To risk identification is the research project is likely to face directly and various risk factors and risk source of implied, for effective judgment, classification, and then identify the nature of the risk process, more intuitive, says is the risk induced by experience and model to find out the root cause of the risk and impact factors, and the qualitative assessment of the consequences caused by these factors, the process is essential for the construction of a risk evaluation index system of the basic work ${ }^{[5]}$.

Risk identification mainly from two aspects of perceived risk and the risk analysis of work to complete the project risk identification. Perceived risk is through various means of risk identification of all existing in the project objective risk analysis and prediction. Risk analysis is to identify the factors that causes the project risk, and according to these risk factors to develop effective countermeasures. When we in risk identification, in identifying directly to implications of the project risk, also want to find the implication that can affect the project risk and the risk of all is not easy to determine. Associated with project risk identification process is the use of all personnel, through scientific means and methods, find out may occur in the process of project, and the smooth completion expected the adverse impact on project objectives all risk events.

\section{POWER ENGINEERING PROJECT RISK EVALUATION MODEL}

\section{A,The choice of evaluation method}

Fuzzy comprehensive evaluation method is based on the fuzzy mathematics theory based on a prediction and evaluation method. Fuzzy comprehensive evaluation method of the basic idea is: in determining the level of evaluation standards and the weights of evaluation factors, on the basis of using the fuzzy set transform principle, the membership degree which is used to describe the factors of fuzzy boundaries, constructs the fuzzy evaluation matrix, by multilayer compound operation, finally decide the rank evaluation objects ${ }^{[6]}$.

\section{B. Evaluation procedure}

\section{(1) Hierarchical structure model is established}

Top: this level is only one element, generally it is the intended target or ideal results to analyze the problem, namely the target layer; The middle layer: this layer includes involved to achieve the goal of the intermediate links, it is composed of several layers, including some principles that should be considered, the rule of the child, also known as the criterion layer ;

Lowest layer: it means for the realization of the goal to choose from a variety of measures, decision-making plan, etc., also measures or solution layer. Judgment matrix representation for A level one element, the level about the status of the relative importance between elements, assuming A elements in A hierarchy, and the next layer of B1, B2,..., 


\begin{tabular}{ccclc}
\hline$a_{k}$ & $B_{1}$ & $B_{2}$ & $\ldots$ & $B_{n}$ \\
\hline$B_{1}$ & $b_{11}$ & $b_{12}$ & $\ldots$ & $b_{1 n}$ \\
$B_{2}$ & $b_{21}$ & $b_{22}$ & $\ldots$ & $b_{2 n}$ \\
$\ldots$ & $\ldots$ & $\ldots$ & $\ldots$ & $\ldots$ \\
$B_{n}$ & $b_{n 1}$ & $b_{n 2}$ & $\ldots$ & $b_{m n}$ \\
\hline
\end{tabular}

$\mathrm{Bn}$, constructing judgment matrix $\mathrm{B}$ to take the following form :

Table. I Constructing judgment matrix B

Which bij $(I=1,2,3, \ldots, n ; j=1,2,3, \ldots, n)$ said for ak, Bi for Bj relatively important numerical form, usually said bij option 1-9 scaling method, various scale meanings are shown in table, II

\begin{tabular}{cl}
\hline scale & \multicolumn{1}{c}{ meaning } \\
\hline 1 & $\begin{array}{l}\text { Said, compared to the I and j factors } \\
\text { are equally important } \\
\text { Said I and j factors compared with } \\
\text { the former slightly more important } \\
\text { than the }\end{array}$ \\
$\begin{array}{l}\text { Said I and j factors, compared to the } \\
\text { former than the latter obviously } \\
\text { important } \\
\text { Said I and j factors, compared to the } \\
\text { former is more important than the }\end{array}$ \\
7 & $\begin{array}{l}\text { latter } \\
\text { Said I and j factors, compared to the } \\
\text { former is definitely important than } \\
\text { the latter }\end{array}$ \\
$\begin{array}{l}\text { Said I and jimportance factors } \\
\text { between the two neighboring } \\
\text { judging scales }\end{array}$ \\
\hline
\end{tabular}

Table. II .1-9 scaling method

Obviously, the judgment matrix are: $\mathrm{bii}=\mathrm{BJJ}=1, \mathrm{bji}=1$ / $\operatorname{bij}(I, j=1,2, \ldots, n)$. The numerical matrix is according to the information Material data, expert opinion and analysis is given after the understanding of the comprehensive balance.

\section{(2)Hierarchical single sort}

Based on hierarchical single order refers to the judgment matrix for a layer of some elements in this level of contact of the element Order of importance weights. Hierarchical single sorting can be summed up in calculating characteristic roots and characteristic vectors of the judgment matrix problem, namely the judgment matrix $\mathrm{B}$, calculate meet: $\mathrm{BW}=\lambda \max \mathrm{W}$ The characteristic roots and characteristic vectors.

Type in the $\lambda$ maxiggest characteristic root for $\mathrm{B}, \mathrm{W}$ for the normalized eigenvector corresponding to the lambda Max, $\mathrm{W}$ component of $\mathrm{Wj}$ as corresponding element weights of single sort. Can prove that, for $\mathrm{n}$ order judgment matrix, its biggest characteristic root is single, $\lambda \max \geq n \lambda \max$ All the characteristic vector of consists of a positive number. In particular, easy judgment matrix is completely consistent, $\lambda \max =n$, In addition to the $\lambda \max$, The rest of the characteristic roots are 0 . To test judgment matrix, consistency need to compute its consistency index $\mathrm{CI}$ :

$$
C I=\frac{\lambda_{\max }-n}{n-1}
$$

$\mathrm{N}$ is the order of judgement matrix, and then calculate the consistency ratio $\mathrm{CR}$ :

$$
C R=\frac{C I}{R I}
$$

Type in the RI as the mean random consistency index, see its value TableIII.

\begin{tabular}{c|c|c|c|c|c|c|c|c|c}
\hline $\begin{array}{l}\text { Order } \\
\text { numbe } \\
\mathbf{r}\end{array}$ & 1 & 2 & 3 & 4 & 5 & 6 & 7 & 8 & 9 \\
\hline $\mathrm{RI}$ & 0 & 0 & 0.52 & 0.89 & 1.12 & 1.26 & 1.36 & 1.41 & 1.45 \\
\hline
\end{tabular}

TableIII Numerical mean random consistency index

when $\mathrm{CR}<0.1$, Argues that the consistency of judgment matrix is satisfied, or need to adjust the judgment matrix, make have satisfactory consistency.

\section{(3)Hierarchy total sorts}

Single sort results, using the same level all levels can be calculated for a layer in the hierarchy weighting of the importance of all elements, that is total sorts. Hierarchy total ordering need to order one by one from top to bottom, to the highest level, the level of single order is the total order. Assume a level all elements A1, A2,... Ai..., Am the level of the total order has been completed, the weight of al, respectively, a2,... Ai.... am and ai corresponds to the element level $\mathrm{B} 1, \mathrm{~B} 2, \ldots \mathrm{Bj} \ldots, \mathrm{Bn}$ single sort as a result, if $\mathrm{Bj}$ here has nothing to do with $\mathrm{Ai}$,

then $b_{j}^{t}=0$, Have a level of sorting table are shown in table 4 below : 
Consistency check for the total sorts of how the results consistency evaluation levels, need to compute and hierarchical single sort of similar test. CI : Total sorts consistency index. RI level total sorts random consistency index. CR level total sorts of random consistency ratio. Its formula, respectively :

$$
C I=\sum_{i=1}^{n} a_{i} C I_{i}, \quad R I=\sum_{i=1}^{m} a_{i} R I_{i}
$$

Type of CIi, RIi respectively with ai corresponds to the consistency of judgement matrix in B level index and consistency index :

$$
C R=\frac{C I}{R I}
$$

When the same $C R<0.1$, Think hierarchy total sorting results have satisfactory consistency, otherwise need to adjust to this level of the judgment matrix, the level of total sorts with satisfactory consistency.

\section{(4)The primary fuzzy evaluation}

Set according to the first in the class $\mathrm{I} j$ factor uij of evaluation, evaluation objects belong to the alternative focus the first k elements for ri membership jk $(I=1,2, \ldots, m, j=1$, $2, \ldots, \mathrm{n} ; \mathrm{k}=1,2, \ldots, \mathrm{p})$, the level of single factor evaluation matrix of fuzzy comprehensive evaluation are as follows:

$$
\boldsymbol{R}_{i}=\left[\begin{array}{cccc}
r_{i 11} & r_{i 12} & \cdots & r_{i 1 p} \\
r_{i 21} & r_{i 21} & \cdots & r_{i 2 p} \\
\cdots & \cdots & \cdots & \cdots \\
r_{i n 1} & r_{i n 2} & \cdots & r_{i n p}
\end{array}\right]
$$

So, the first class I factors of fuzzy comprehensive evaluation sets:

$$
B_{i}=A \circ R_{i}=\left(a_{i 1}, a_{i 2}, \ldots, a_{i n}\right)\left[\begin{array}{cccc}
r_{i 11} & r_{i 12} & \cdots & r_{i 1 p} \\
r_{i 21} & r_{i 21} & \cdots & r_{i 2 p} \\
\ldots & \cdots & \cdots & \cdots \\
r_{i n 1} & r_{i n 2} & \cdots & r_{i n p}
\end{array}\right]\left(b_{i 1}, b_{i 2}, \ldots, b_{i p}\right)
$$

(5)The secondary fuzzy evaluation

Level fuzzy comprehensive evaluation is only on the class of the various factors synthetically, in order to comprehensive consideration of various kinds of factors, must also be in class between synthetically, this is the second comprehensive evaluation. Obviously, the secondary fuzzy comprehensive evaluation of single factor evaluation should be corresponding level fuzzy comprehensive evaluation matrix. So the secondary fuzzy comprehensive evaluation of single factor

\begin{tabular}{cccccc}
\hline & $A$ & $A_{2}$ & $A_{i}$ & $A$ & Blevel \\
& $a_{1}$ & $a_{2}$ & $a_{i}$ & $m^{2}$ & Total sorts \\
& $b_{1}^{1}$ & $b_{1}^{2}$ & $b_{1}^{i}$ & $b_{1}^{m}$ & $\sum_{i=1}^{m} a_{i} b_{1}^{i}$ \\
$\ldots$ & $\ldots$ & $\ldots$ & $\ldots$ & $\ldots$ & \\
$B_{j}$ & $b_{j}^{1}$ & $b_{j}^{2}$ & $b_{j}^{i}$ & $b_{j}^{m}$ & $\sum_{i=1}^{m} a_{i} b_{j}^{i}$ \\
$\ldots$ & $\ldots$ & $\ldots$ & $\ldots$ & $\ldots$ & $\sum_{i=1}^{m} a_{i} b_{n}^{i}$ \\
$B_{n}$ & $b_{n}^{1}$ & $b_{n}^{2}$ & $b_{n}^{i}$ & $b_{n}^{m}$ & $\sum^{2}$ \\
\hline
\end{tabular}

Table.IV Hierarchy total sorts

evaluation matrix, should be level fuzzy comprehensive evaluation.

$$
R=\left[\begin{array}{c}
B_{1} \\
B_{2} \\
\vdots \\
B_{\mathrm{m}}
\end{array}\right]=\left[\begin{array}{c}
A_{1} \circ R_{1} \\
A_{2} \circ R_{2} \\
\vdots \\
A_{m} \circ R_{m}
\end{array}\right]
$$

Then get the secondary fuzzy comprehensive evaluation set

$$
B=A \circ R=A \circ\left[\begin{array}{c}
A_{1} \circ R_{1} \\
A_{2} \circ R_{2} \\
\vdots \\
A_{m} \circ R_{m}
\end{array}\right]\left(b_{1}, b_{2}, \ldots, b_{p}\right)
$$

If each factors also need to be classified, modeled after the above steps for secondary even more multi-level fuzzy comprehensive evaluation.

By the above calculated the indexes of comprehensive risk value, and through expert investigation concluded that the overall risk level of value, criterion layer are calculated respectively each index of the comprehensive risk value, finally it is concluded that the project overall risk level, then determine the risk level of electric power engineering project. And according to the risk assessment results, corresponding to find out the rectification power engineering project risk measures, in order to better improve the deficiency in the electric power project, more give full play to the importance of project risk evaluation for power engineering project and scientific.

\section{References}

[1] Zhao Shuhua . Electric power engineering construction process management implementation summary [J]. Electric power construction , 2010, (2) : 211-212. 
[2] Qiu Yuanhua, jasmine shen. An introduction to modern project management $[\mathrm{M}]$. Mechanical industry press, Beijing, 2002 : 254-259.

[3] Abraham Warszawski. Rafael Sacks Practical Multifactor Approach to Evaluating Risk of Investment in Engineering Projects[J]. Construction and Management, 2008,

(3) : 148-154.

[4] Robert L.K. Tiong. Risk assessment on contractor's pricing Statagies[J]. Journal of Construction Economics and Management, 2008, (11) : 234-240.
[5] Irem Dike mnzdoganmetal. A decision support frame work for Project Sponsors in the planning stage of build operate transfer ( BOT ) projects[J]. Journal of construction Economics and Management, 2009 , (2) : 96-101.

[6] Mob C. Ketal. Practices, barriers and benefits of risk management process in building services cost estimation[J].Journal of Construction Management and Economics, 2009, (4) : 214-219. 